\title{
Reduced in vitro susceptibility to artemisinin derivatives associated with multi-resistance in a traveller returning from South-East Asia
}

\author{
Bruno Pradines ${ }^{1,2^{*}}$, Lionel Bertaux ${ }^{2,3}$, Christelle Pomares ${ }^{4,5}$, Pascal Delaunay ${ }^{4,5}$ and Pierre Marty ${ }^{4,5}$
}

\begin{abstract}
Decreased in vitro susceptibility to dihydroartemisinin (21.2 nM) and artesunate (16.3 nM) associated with decreased susceptibility or resistance to quinine (1131 nM), mefloquine (166 nM), lumefantrine (114 nM), pyronaridine $(70.5 \mathrm{nM})$ and piperaquine $(91.1 \mathrm{nM})$ is reported in a patient returning from South-East Asia after trekking along the Mekong from the south of Laos to the north of Thailand. Decreased in vitro susceptibility to artemisinin derivatives did not appear to be mediated by the number of copies of pfmdr1 or pfATPase6, pfcrt, pfmdr1 or pfmrp polymorphism. The high $I C_{50}$ to mefloquine of this Asian isolate was not associated with pfmdr 1 copy number. Pfnhe-1 microsatellite ms4760 showed a profile 7 (ms4760-7) with three repeats of DNNND and one repeat of DDDNHNDNHNN, which is associated with high quinine reduced susceptibility. The patient recovered in three days without relapse after treatment with the association of quinine and doxycycline. Decreased in vitro susceptibility to quinine and the delayed effect of doxycycline may both have contributed to the delayed parasite clearance time, D4 (0.5\%) and D7 (0.004\%). The in vitro data, with $I_{50}$ for dihydroartemisinin and artesunate were up to ten times those of the reference clone W2, which suggests that this isolate may be resistant to artemisinin derivatives, associated with a decreased susceptibility to quinine.
\end{abstract}

\section{Background}

Artemisinin-based combination therapy (ACT) is now recommended by the World Health Organization as firstline treatment of uncomplicated falciparum malaria in all areas in which malaria is endemic. However, recent reports from Cambodia of delayed parasite clearance after treatment by ACT have now been confirmed [1]. The resistant phenotype is not yet reflected by the results of conventional in vitro drug susceptibility assays. Parasites with slow clearance rate after ACT did not show in vitro decreased susceptibility [1]. In vitro decreased susceptibility to artemisinin derivatives was never or very rarely reported in Cambodia [1-4]. No molecular marker has been identified, which impedes surveillance studies to monitor the spread of artemisinin resistant phenotype. Decrease of in vitro susceptibility to dihydroartemisinin

\footnotetext{
* Correspondence: bruno.pradines@free.fr

'Unité de Recherche en Biologie et Epidémiologie Parasitaires - Unité de Recherche pour les Maladies Infectieuses et Tropicales Emergentes - UMR 6236, Institut de Médecine Tropicale du Service de Santé des Armées, Marseille, France

Full list of author information is available at the end of the article
}

and artesunate, associated with reduced susceptibility to standard anti-malarials, such as quinine, mefloquine and lumefantrine, and new drugs, such as pyronaridine and piperaquine, is reported here.

\section{Case presentation}

A 52-year old female visited rural areas in Laos (Nov 9 to 12, 2009), Cambodia (Nov 12 to 29) and Thailand (Nov 29 to Dec 1). She took part in trekking along the Mekong from the south of Laos to the north of Thailand. The patient presented with fever since November 29 and was hospitalized (Dec 2) in intensive care unit (Centre Hospitalier Universitaire l'Archet, Nice, France) for complicated malaria (15\% parasitaemia and altered consciousness). The patient used irregularly doxycycline (100 $\mathrm{mg} /$ day) as chemoprophylaxis. The patient was treated by intra-venous quinine chlorhydrate $(25 \mathrm{mg} / \mathrm{kg} /$ day $)$ and doxycycline $(200 \mathrm{mg} /$ day) for seven days. The patient recovered in three days without relapse and was discharged.

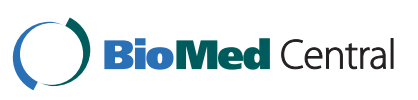


Plasmodium falciparum parasites were identified at Day 0 (15\%), D4 (0.5\%) and D7 (0.004\%) but were not detected at D43.

\section{Methods}

In vitro testing of drug susceptibility was performed by the standard 42-hour ${ }^{3} \mathrm{H}$-hypoxanthine uptake inhibition method [5]. Susceptibility to dihydroartemisinin, artesunate, and ten standard or new anti-malarial drugs, ie chloroquine, quinine, mefloquine, lumefantrine, monodesethylamodiaquine (biologically active metabolite of amodiaquine), pyronaridine, piperaquine, atovaquone, doxycycline and pyrimethamine, was assessed. The laboratory-adapted clone W2, tested on the same day, was used as a reference. Isolates from imported malaria, tested on the same batch of plates, were used as comparators.

Polymorphisms of pfcrt, pfmdr1, pfmrp and pfnhe-1, involved in quinoline resistance, and in pfATPase6, postulated to be involved in artemisinin resistance, and the copy number of $p f m d r 1$ were assessed [6].

The French malaria consensus [7] and the WHO [8] recommend to clinically examine patient and control parasitaemia at D0, D3, D7 and D28 to evaluate anti-malarial efficacy. Blood controls were performed at D0, D4, D7 and D43. The genotyping of parasites was assessed at D0, D4 and D7 using six microsatellite loci (microsatellites 7A11, pf2689, pf2802, C4M79, TRAP, C4M69) [9], msp1 and msp2 [10].

\section{Consent}

Informed consent was not required as the sampling procedures and testing are part of the French national recommendations for the care and surveillance of malaria.

\section{Results}

This isolate showed decreased susceptibility to dihydroartemisinin $(21.2 \mathrm{nM})$ and artesunate $(16.3 \mathrm{nM})$ associated with decreased susceptibility or resistance to quinine (1131 nM), mefloquine (166 nM), lumefantrine (114 nM), pyronaridine $(70.5 \mathrm{nM})$ and piperaquine $(91.1 \mathrm{nM})$ with high ratio in comparison with W2 (Table 1$)$. These $\mathrm{IC}_{50}$ and W2 ratios were higher than those of other imported isolates.

Mutations were not identified in $p f m d r 1, p f c r t$ and pfmrp genes. Only one copy of $p f m d r 1$ was found. Two synonymous mutations were detected in pfATPase 6 (N460N and I898I), which were previously described [11]. Pfnhe-1 microsatellite ms4760 showed a profile 7 (ms4760-7) with three repeats of DNNND and one repeat of DDDNHNDNHNN, which is associated with high quinine reduced susceptibility [12].

Parasitaemia was controlled at Day 0, D4, D7 and D43. Monoclonal and identical parasites were identified at D0 (15\% of parasitaemia), D4 (0.5\%) and D7 (0.004\%) by using microsatellites 7A11, pf2689, pf2802, C4M79, TRAP, C4M69 and $m s p 1$ and $m s p 2$. No parasite was detected at D43.

\section{Conclusion}

This isolate showed reduced susceptibility to artemisinin derivatives, but also to other ACT components commonly used in Asia or in clinical trials, such as mefloquine, lumefantrine, pyronaridine or piperaquine. Surprising, this isolate was susceptible in vitro to chloroquine and monodesethylamodiaquine. It was also susceptible to doxycycline. Plasmodium falciparum parasite with high $\mathrm{IC}_{50}$ to artemisinin and artemether $(20.1 \mathrm{nM}$ and $21.4 \mathrm{nM}$, respectively), but with low $\mathrm{IC}_{50}$ to dihydroartemisinin and artesunate (1.8 $\mathrm{nM}$ and $6.2 \mathrm{nM}$, respectively) was recently isolated in a traveller returning from Nigeria, who took artesunate prophylactically (two $50 \mathrm{mg}$ tablets weekly for 4 weeks) [13]. Yet, recent clinical trials of oral artesunate monotherapy suggest that the loss of ACT efficacy might result from decreased efficacy of artemisinin derivatives $[1,3]$. The median parasite clearance time was 36 hours longer in patients from Western Cambodia, where the efficacy of ACT is decreasing [1]. Nevertheless, this phenomenon was not correlated with artemisinin derivatives $\mathrm{IC}_{50}$.

Only one copy of $p f m d r 1$ was found. The high $\mathrm{IC}_{50}$ to mefloquine of this Asian isolate was not associated with pfmdr1 copy number. Pfnhe-1 microsatellite ms 4760 showed a profile 7 (ms4760-7) with three repeats of DNNND and one repeat of DDDNHNDNHNN, which is associated with high quinine reduced susceptibility [12]. Two repeats of DNNND were seen to be associated with high $\mathrm{IC}_{50}$ in quinine clinical failure in traveller from Senegal [14].

The persistence of parasites seven days after the start of treatment with quinine chlorhydrate and doxycycline, but without clinical signs, is consistent with the high $\mathrm{IC}_{50}$ and with the profile ms 4760 of pfnhe-1. The action of doxycycline is delayed. There is a relationship between the amount and duration of exposure and the effect of doxycycline on the erythrocytic stages with an increased activity during the second cycle. Doxycycline has been shown to exert its effect during the first $48 \mathrm{~h}$, but is only detectable in second-generation parasites near the 96 hour time point [15-17]. The French malaria consensus recommends quinine associated with doxycycline for Asian and SouthAmerican P. falciparum (and not only quinine as for African parasites). Clinical failure with quinine has been shown in a patient returning from French Guiana treated by quinine only [18]. The patient recovered in three days without relapse and left intensive care due to the treatment she received, the association of quinine and doxycycline, as recommended by the French malaria consensus. In vitro quinine $\mathrm{IC}_{50}$ and $p$ fnhe- $1 \mathrm{~ms} 4760$ analysis suggest a reduced susceptibility to quinine. This decreased 
Table 1 In vitro susceptibility to standard antimalarial drugs of the multidrug-resistant isolate in comparison with P.falciparum W2 clone and $P$. falciparum isolates tested with the same plate batches

\begin{tabular}{|c|c|c|c|c|c|c|}
\hline Drugs & $\begin{array}{c}\text { Isolate } \\
\text { IC }_{50}\end{array}$ & Ratio $I_{50}$ Isolate/W2 & $\begin{array}{l}\text { W2* } \\
\text { IC }{ }_{50}\end{array}$ & $\begin{array}{c}\text { Isolates** } \\
\text { Mean IC } \text { IC }_{50}(\mathrm{Cl} 95 \%)\end{array}$ & Ratio $\mathrm{IC}_{50}$ Isolates/W2 & $\begin{array}{l}\text { Resistance } \\
\text { cut-off }\end{array}$ \\
\hline Dihydroartemisinin & $21.2 \mathrm{nM}$ & 11.8 & $1.8 \mathrm{nM}$ & $2.2 \mathrm{nM}(1.3-3.7)$ & 1.2 & $>10.5 \mathrm{nM}$ \\
\hline Artesunate & $16.3 \mathrm{nM}$ & 10.2 & $1.6 \mathrm{nM}$ & $1.9 \mathrm{nM}(1.0-3.2)$ & 1.2 & $>10.5 \mathrm{nM}$ \\
\hline Quinine & $1131 \mathrm{nM}$ & 1.5 & $731 \mathrm{nM}$ & $201 \mathrm{nM}(131-307)$ & 0.3 & $>800 \mathrm{nM}$ \\
\hline Mefloquine & 166 nM & 4.5 & $36.6 \mathrm{nM}$ & 26.0 nM (15.9-42.5) & 0.7 & $>30 \mathrm{nM}$ \\
\hline Lumefantrine & $114 \mathrm{nM}$ & 4.0 & $28.4 \mathrm{nM}$ & 23.9 nM (14.1-40.8) & 0.8 & $>150 \mathrm{nM}$ \\
\hline Pyronaridine & $70.5 \mathrm{nM}$ & 7.8 & $9.0 \mathrm{nM}$ & 26.2 nM (15.4-44.6) & 2.9 & ND \\
\hline Piperaquine & $91.1 \mathrm{nM}$ & 3.3 & $27.3 \mathrm{nM}$ & 66.2 nM (34.7-126.3) & 2.4 & ND \\
\hline Chloroquine & $63 \mathrm{nM}$ & 0.14 & $449 \mathrm{nM}$ & 63 nM (29-138) & 0.1 & $>100 \mathrm{nM}$ \\
\hline Monodesethylamodiaquine & $34.4 \mathrm{nM}$ & 0.54 & $63.2 \mathrm{nM}$ & 32.4 nM (19.2-54.8) & 0.5 & $>80 \mathrm{nM}$ \\
\hline Atovaquone & $2.21 \mathrm{nM}$ & 0.74 & $2.99 \mathrm{nM}$ & 1.48 nM (1.06-2.07) & 0.5 & $>490 \mathrm{nM}$ \\
\hline Doxycycline & $18.5 \mu \mathrm{M}$ & 1.5 & $12.1 \mu \mathrm{M}$ & $10.0 \mu \mathrm{M}(7.8-12.9)$ & 0.8 & $>35 \mu \mathrm{M}$ \\
\hline Pyrimethamine & 497 nM & 0.04 & $12621 \mathrm{nM}$ & 107 nM (7-1681) & 0.01 & $>2000 \mathrm{nM}$ \\
\hline
\end{tabular}

* The laboratory-adapted clone $\mathrm{W} 2$, tested on the same day, was used as a reference.

** Values are geometric mean and $95 \%$ confidence interval of 16 isolates from imported malaria, tested on the same batch of plates, and used as comparators. ND: not determined

susceptibility to quinine and the delayed effect of doxycycline may both have contributed to the delayed parasite clearance time, D4 (0.5\%) and D7 (0.004\%).

Decreased in vitro susceptibility to artemisinin derivatives did not appear to be mediated by the number of copies of pfmdr1 or pfATPase6 polymorphism. The in vitro data, with $\mathrm{IC}_{50}$ for dihydroartemisinin and artesunate up to ten times those of the reference clone W2 or the geometric mean of the other isolates, suggest that this isolate could be resistant to artemisinin derivatives, even if there is no evidence that this isolate was clinically resistant to ACT, associated with decreased susceptibility to quinine. And its association with the other in vitro decreased susceptibilities is alarming, especially with the components of ACT used in Asia.

\section{Acknowledgements and Funding}

The authors thank R Amalvict, E Baret, N Benoit, H Bouchiba, S Charras, J Cren and D Travers from IRBA and E Cua, H Hyvernat, C Dubois, S Melhem from CHU Nice for technical support.

This study was supported by the Institut National de Veille Sanitaire.

\section{Author details}

'Unité de Recherche en Biologie et Epidémiologie Parasitaires - Unité de Recherche pour les Maladies Infectieuses et Tropicales Emergentes - UMR 6236, Institut de Médecine Tropicale du Service de Santé des Armées, Marseille, France. ${ }^{2}$ Centre National de Référence du Paludisme, Marseille, France. ${ }^{3}$ Unité de Recherche en Physiologie et Pharmacocinétique Parasitaires - UMR-MD3 Relations Hôte-Parasites - Pharmacologie et Thérapeutique, Institut de Médecine Tropicale du Service de Santé des Armées, Marseille, France. ${ }^{4}$ Laboratoire de Parasitologie-Mycologie, Centre Hospitalier Universitaire l'Archet, Nice, France. Inserm U 895, Equipe 6, Université de Nice Sophia Antipolis, Nice, France.

\section{Authors' contributions}

BP carried out in vitro testing of drug susceptibility and drafted the manuscript. LB carried out the molecular genetic studies. CP, PD and PM carried out diagnostic, monitoring of the patient, collection of clinical and epidemiological data and drafted the manuscript. All authors read and approved the final manuscript.

\section{Competing interests}

The authors declare that they have no competing interests.

Received: 20 July 2011 Accepted: 18 September 2011

Published: 18 September 2011

\section{References}

1. Dondorp AM, Nosten F, Yi P, Das D, Phyo AP, Tarning J, Lwin KM, Ariey F, Hanpithakpong W, Lee SJ, Ringwald P, Silamut K, Imwrong M, Chotivanish K, Lim P, Herdman T, An SS, Yeung S, Singhasivanon P, Day NPJ, Lindegardh N, Socheat D, White NJ: Artemisinin resistance in Plasmodium falciparum malaria. N Engl J Med 2009, 361:455-467.

2. Jambou R, Legrand E, Niang M, Khim N, Lim P, Volney B, Ekala MT, Bouchier C, Esterre P, Fandeur T, Mercereau-Puijalon O: Resistance of Plasmodium falciparum field isolates to in vitro artemether and point mutations of the Serca-type PfATPase6. Lancet 2005, 366:1960-1963.

3. Noedl H, Se Y, Schaecher K, Smith BL, Socheat D, Fukuda MM: Evidence of artemisinin-resistant malaria in western Cambodia. N Engl J Med 2008, 359:2619-2620.

4. Noedl H, Socheat $D$, Satimai W: Artemisinin-resistant malaria in Asia. $N$ Eng J Med 2009, 361:540-541.

5. Briolant S, Baragatti M, Parola P, Simon F, Tall A, Sokhna C, Mamfoumbi MM, Koeck JL, Delmont J, Spiegel A, Castello J, Gardair JP, Trape JF, Kombila M, Minodier P, Fusai T, Rogier C, Pradines B: A multinormal distribution model suitable for the distribution of Plasmodium falciparum in vitro chemosusceptibility to doxycycline. Antimicrob Agents Chemother 2009, 53:688-695.

6. Pradines $B$, Dormoi J, Briolant $S$, Bogreau $H$, Rogier $C$ : La résistance aux antipaludiques. Rev Fr Lab 2010, 422:51-62.

7. Management and prevention of imported Plasmodium falciparum malaria: Recommendations for clinical practice 2007 (revision 2007 of the 1999 consensus conference). Med Mal Infect 2008, 38:68-117.

8. World Health Organization: Methods for surveillance of antimalarial drug efficacy.[http://apps.who.int/malaria/docs/drugresistance/Protocol2009.pdf].

9. Bogreau H, Renaud F, Bouchiba H, Durand P, Assi SB, Henry MC, Garnotel E, Pradines B, Fusai T, Wade B, Adehossi E, Parola P, Kamil MA, Puijalon O, Rogier C: Genetic diversity and structure of African Plasmodium falciparum populations in urban and rural areas. Am J Trop Med Hyg 2006, 74:953-959.

10. Henry M, Diallo I, Bordes J, Ka S, Pradines B, Diatta B, M'Baye PS, Sane M, Thiam M, Gueye PM, Wade B, Touze JE, Debonne JM, Rogier C, Fusai T: 
Urban malaria in Dakar, Senegal: chemosusceptibility and genetic diversity of Plasmodium falciparum isolates. Am J Trop Med Hyg 2006, 75:146-151.

11. Bertaux L, Quang LH, Sinou V, Xuan Thanh N, Parzy D: New pfATP6 mutations found in Plasmodium falciparum isolates from Vietnam. Antimicrob Agents Chemother 2009, 53:4570-4571.

12. Henry M, Briolant S, Zettor A, Pelleau S, Baragatti M, Baret E, Mosnier J, Amalvict R, Fusai T, Rogier C, Pradines B: Plasmodium falciparum $\mathrm{Na}^{+} / \mathrm{H}^{+}$ exchanger 1 transporter is involved in reduced susceptibility to quinine. Antimicrob Agents Chemother 2009, 53:1926-1930.

13. Shahinas D, Lau R, Khairnar K, Handock D, Pillai DR: Artesunate misuse and Plasmodium falciparum malaria in traveller returning from Africa. Emerg Infect Dis 2010, 16:1608-1610.

14. Pradines B, Pistone T, Ezzedine K, Briolant S, Bertaux L, Receveur MC, Parzy D, Millet $\mathrm{P}$, Rogier C, Malvy D: Quinine-resistant malaria in traveler returning from Senegal, 2007. Emerg Infect Dis 2010, 16:546-548.

15. Dahl E, Rosenthal P: Multiple antibiotics exert delayed effects against the Plasmodium falciparum apicoplast. Antimicrob Agents Chemother 2007, 51:3485-3490

16. Pradines B, Spiegel A, Rogier C, Tall A, Mosnier J, Fusai T, Trape JF, Parzy D: Antibiotics for prophylaxis of Plasmodium falciparum infections: in vitro activity of doxycycline against Senegalese isolates. Am J Trop Med Hyg 2000, 62:82-85.

17. Pradines B, Rogier C, Fusai T, Mosnier J, Daries W, Baret E, Parzy D: In vitro activities of antibiotics against Plasmodium falciparum are inhibited by iron. Antimicrob Agent Chemother 2001, 45:1746-1750.

18. Bertaux L, Kraemer P, Taudon N, Trignol A, Martelloni M, Saidi R, Parzy D, Pradines $B$, Simon F: Quinine-resistant malaria in traveler returning from French Guiana, 2010. Emerg Infect Dis 2011, 17:943-945.

doi:10.1186/1475-2875-10-268

Cite this article as: Pradines et al: Reduced in vitro susceptibility to artemisinin derivatives associated with multi-resistance in a traveller returning from South-East Asia. Malaria Journal 2011 10:268.

\section{Submit your next manuscript to BioMed Central and take full advantage of:}

- Convenient online submission

- Thorough peer review

- No space constraints or color figure charges

- Immediate publication on acceptance

- Inclusion in PubMed, CAS, Scopus and Google Scholar

- Research which is freely available for redistribution

Submit your manuscript at www.biomedcentral.com/submit 